Original Papers

\title{
Rapid Assay of Trace Ceruloplasmin Using an Immunonanogold Resonance Scattering Spectral Probe
}

\author{
Zhiliang JIANG, ${ }^{*} * * \dagger$ Lili WeI, ${ }^{*}$ and Aihui LIANG $* *$ \\ *School of Environment and Resource, Guangxi Normal University, Guilin 541004, China \\ **Department of Material and Chemical Engineering, Guilin University of Technology, Guilin 541004, China
}

\begin{abstract}
Nanogold particles of size $15 \mathrm{~nm}$ were used to label goat anti-human ceruloplasmin (GCP) to obtain an immunonanogold probe (AuGCP) for ceruloplasmin (CP). In a pH 7.8 citric acid- $\mathrm{Na}_{2} \mathrm{HPO}_{4}$ buffer solution and in the presence of polyethylene glycol (PEG), an immunoreaction between AuGCP and CP took place, and the released nanogold particles aggregated to bigger clusters, which caused the resonance scattering (RS) intensity at $552 \mathrm{~nm}\left(I_{552 \mathrm{~nm}}\right)$ to be enhanced greatly. The enhanced intensity $\Delta I$ was proportional to the $\mathrm{CP}$ concentration $\left(C_{\mathrm{CP}}\right)$ in the range from 0.0030 to 1.26 $\mu \mathrm{g} / \mathrm{mL}$, with a regress equation of $\Delta I=101.0 C_{\mathrm{CP}}+1.8$, a correlation coefficient of 0.9970 , and a detection limit of 1.1 $\mathrm{ng} / \mathrm{mL} \mathrm{CP}$. This simple and sensitive RS immunoassay was applied to the determination of $\mathrm{CP}$ in human plasma, with satisfactory results.
\end{abstract}

(Received April 8, 2008; Accepted August 6, 2008; Published April 10, 2009)

\section{Introduction}

Ceruloplasmin $(\mathrm{CP})$, a copperish $\alpha_{2}$-glycoprotein, which is mainly synthesized by the liver, ${ }^{1}$ existing in the plasma of all vertebrate species, exhibited oxidase activity toward some aromatic amines and phenols. Due to its higher oxidizing activity, CP is also called ferroxidase. Recent studies showed that $\mathrm{CP}$ was helpful to $\mathrm{Fe}$ metabolism because of its catalytic oxidation of $\mathrm{Fe}$ (II) to $\mathrm{Fe}(\mathrm{III}){ }^{2}$ Nevertheless, although the precise physiological functions of $\mathrm{CP}$ are unknown, it has antioxidant activity by promoting $\mathrm{Fe}$ mobilization $^{3}$ and preventing the metal-catalysis of free radicals and the formation of lipid peroxide in tissue. Therefore, CP played an important role in maintaining body homoeostasis and guaranteeing its normal function. ${ }^{4}$ In fact, $\mathrm{CP}$ is an acute-phase protein with its serum concentration that increases during pregnancy, infection, tissue injury, and certain malignant disorders. ${ }^{2} \mathrm{CP}$ is considered as a useful laboratory test for Wilson's disease and Menkes' syndrome. Its serum concentration is decreased in up to $95 \%$ of symptomatic patients. 5,6 In addition, CP may be decreased in other disease states, like malnutrition, severe liver diseases and nephrotic syndrome. ${ }^{5}$ Furthermore, the content of CP may also be low in patients with hereditary hypoceruloplasminemia. Thus, the measurement of $\mathrm{CP}$ is of great significance in the diagnosis of some diseases. At present, several methods have been employed for the determination of CP in human serum, including enzymatic assay and immunoassay. Based on the enzymatic oxidase activity of $\mathrm{CP}$ on the substrate of $p$ phenylenediamine (PPD), a PPD colorimetry was established. ${ }^{7}$ However, the assay is non-specific, and some anions inhibited oxidative activity. Schosinsky et al. have improved the method with $N, N^{\prime}$-dimethylphenylenediamine (DPPD) ${ }^{3}$ as a substrate,

† To whom correspondence should be addressed.

E-mail: zljiang@mailbox.gxnu.edu.cn because the product is more stable. ${ }^{8,9}$ Immunoreaction has been widely used in biochemical analysis, since it has high specificity. To enhance the sensitivity, radioactive, fluorescence and enzyme-labeled assays were developed. ${ }^{10-13}$ Several immunoassays, including spectrophotometry, immunoturbidimetric assay, rocket immunoelectrophoresis, radial immunodiffusion, kinetic turbidimetry and bi-antibody radioimmune methods have been reported for $\mathrm{CP}^{6,14-19}$ Among these methods, the immunoturbidimetric assay is simple and rapid, but requires large amounts of precious antisera. Radial immunodiffusion is simple and more sensitive, but it was time-consuming and a harmful reagent was used. Rocket immunoelectrophoresis has a high specificity, and uses smaller amounts of antisera (5 - 10 $\mu \mathrm{L}$ ), but the requirements of experiment are very strict.

Nanogold particles have become the fourth immune label because of their specific physical and chemical characteristics, high electron density and good biocompatibility. At present, the detection techniques for the nanogold-labeled immunoassay mainly include spectrophotometry, ${ }^{20}$ chemiluminescence, ${ }^{21,22}$ mass spectrometry, ${ }^{23,24}$ resonance scattering spectrometry ${ }^{25,26}$ and electrochemical methods. ${ }^{27,28}$ A resonance scattering (RS) technique was sensitive, rapid and simple, and has been applied to the analysis of trace inorganic and organic compounds. ${ }^{29-33}$ Recently, coupling immunoreaction and the RS effect of nanogold, an immunonanogold RS spectral assay, has been developed, with higher sensitivity and selectivity. ${ }^{34,35}$ However, there has been no report about the immunonanogold RS assay for CP. In the present work, a highly sensitive and selective RS method for CP was established.

\section{Experimental}

\section{Reagents and apparatus}

Goat anti-human ceruloplasmin (GCP) and ceruloplasmin (CP) were purchased from Beijia Biological Reagents Ltd. Co., 
Shanghai, China. A $10.8 \mu \mathrm{g} / \mathrm{mL}$ CP working solution was obtained by diluting the stock solution $(360 \mathrm{mg} / \mathrm{mL})$ with water. A working GCP solution was prepared as follows: we put 1.0 $\mathrm{mL}$ of the GCP serum into a $25-\mathrm{mL}$ volumetric flask, and diluted to the marker with water. Then, $1.0 \% \mathrm{HAuCl}_{4}$ (National Pharmaceutical Group Chemical Reagents Co., China) and 1.0\% trisodium citrate (Shanghai Chemical Reagent Plant, Shanghai, China) were used to prepare nanogold. A $0.10 \mathrm{~mol} / \mathrm{L} \mathrm{Na}_{2} \mathrm{HPO}_{4}$ solution and $0.10 \mathrm{~mol} / \mathrm{L}$ citric acid were used to prepare different $\mathrm{pH}$ phosphate buffer solutions according to a certain volume ratio. PEG-6000, PEG-4000, PEG-10000, PEG-20000 and $\mathrm{KCl}$ were also used. All reagents were of analytical grade and the water was doubly distilled.

A Model Cary Eclipse fluorescence spectrophotometer (Varian Company, Palo Alto, CA) was used to record the RS intensity, with excited and emission slits of $5 \mathrm{~nm}$, and PMT a voltage of $400 \mathrm{~V}$. A Model H-600 transmission electron microscope (TEM) (Electronic Stock Ltd. Co., Japan), a Model 79-1 magnetic heat agitator (Zhongda Instrumental Plant, Jiangsu, China), and a Model SK8200LH ultrasonic reactor (Kedao Ultrasonic Instrument Ltd. Co., Shanghai, China) were used.

\section{Preparation of the colloidal gold}

Nanogold particles with sizes of 10,15 and $30 \mathrm{~nm}$ were prepared by the addition of $6.0,3.0$ and $2.0 \mathrm{~mL} 1 \%$ trisodium citrate, respectively, according to a procedure described in a reference. ${ }^{35}$ All glassware used in the following procedures were thoroughly cleaned with freshly prepared $\mathrm{HNO}_{3}-\mathrm{HCl}$ $\left(\mathrm{HNO}_{3}: \mathrm{HCl}=1: 3\right.$, by volume $)$ and washed with double-distilled water. In brief, $100 \mathrm{~mL}$ of a $0.01 \% \mathrm{HAuCl}_{4}$ solution was heated to boiling. After 2 min, a certain amount of a $1 \%$ sodium citrate solution was added quickly with vigorous stirring. The color immediately changed from pale yellow to purple, then to dark red, and to bright red at the end. After about $7 \mathrm{~min}$, the heating was stopped. The solution was stirred continuously until being cooled to room temperature. Finally, the cooled solution was diluted with water to $100 \mathrm{~mL}$ and stored in a refrigerator at $4^{\circ} \mathrm{C}$.

\section{Preparation of the immunonanogold probe for GCP}

Effect of the $\mathrm{pH}$ on the labeling. Because the combination of nanogold with GCP is done by physical force, a successful combination depends on the $\mathrm{pH}$. The RS technique was used to test the influence of different $\mathrm{pH}$ conditions on nanogold labeling. We adjusted the $\mathrm{pH}$ from 4.0 to 10.0 in $1.0 \mathrm{~mL}$ of a $57.96 \mu \mathrm{g} / \mathrm{mL}$ nanogold solution. When the $\mathrm{pH}$ was $<8.5$, the addition of a GCP working solution did not coat the nanogold particle and the RS intensity at $552 \mathrm{~nm}\left(I_{552 \mathrm{~nm}}\right)$ was greatly enhanced since nanogold aggregated when $100 \mu \mathrm{L}$ of $10 \% \mathrm{KCl}$ was added. When $\mathrm{pH}$ was $>8.5$, the $I_{552 \mathrm{~nm}}$ was least and stable. It could be interpreted that the coating of nanogold particles by GCP prevented the aggregation of nanogold particles by the $\mathrm{KCl}$. A pH of 8.5 was considered to be suitable for labeling GCP.

Selection of GCP amounts. The effect of 0, 5, 10, 15, 20, 25, $30,35,40,45,50$ and $55 \mu \mathrm{L}$ GCP working solutions on the $I_{552 \mathrm{~nm}}$ was considered. $I_{552 \mathrm{~nm}}$ was stronger in tubes with $0-25$ $\mu \mathrm{L}$ GCP working solutions than those with $30-55 \mu \mathrm{L}$ GCP working solutions, which remained stable. In the experiment, a $30.0 \mu \mathrm{L} \mathrm{GCP}$ working solution was chosen for labeling $1.0 \mathrm{~mL}$ of nanogold in sizes of 10 and $15 \mathrm{~nm}$; a $45.0-\mu \mathrm{L}$ GCP working solution was needed when labeling $1.0 \mathrm{~mL}$ of nanogold for a size of $30 \mathrm{~nm}$.

Preparation of the $15 \mathrm{~nm}$ immunonanogold. We adjusted 100 $\mathrm{mL}$ of a nanogold solution to $\mathrm{pH} 8.5$ under magnetic stirring by adding $3.2 \mathrm{~mL}$ of $0.1 \mathrm{~mol} / \mathrm{L} \mathrm{K}_{2} \mathrm{CO}_{3}$ solutions. We then added

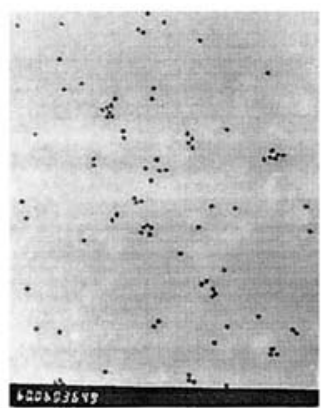

A

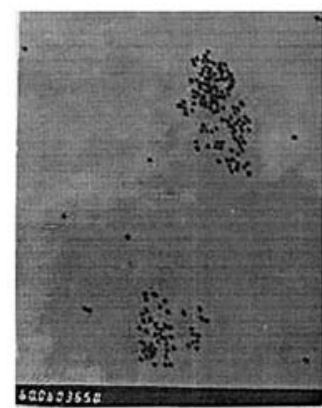

B
Fig. 1 TEM of AuGCP and AuGCP-CP (magnified 60000 times). A, AuGCP; B, AuGCP-CP system.

$3.0 \mathrm{~mL}$ of a GCP working solution slowly to the above colloidal gold solution, while controlling the dropping time to within 5 min. After stirring for about $6 \mathrm{~min}$, we added $1.80 \mathrm{~mL}$ of $3 \%$ PEG-20000 as a stabilizer, to a final concentration of $0.05 \%$. The mixture was stirred for $15 \mathrm{~min}$ and stored in a refrigerator at $4^{\circ} \mathrm{C}$.

\section{Procedure}

A $0.30 \mathrm{~mL}$ pH 7.8 citric acid- $\mathrm{Na}_{2} \mathrm{HPO}_{4}$ buffer solution, 0.60 $\mathrm{mL}$ of a $53.58 \mu \mathrm{g} / \mathrm{mL}$ AuGCP (calculated as $\mathrm{Au}$ ) solution, a certain quantity of the $\mathrm{CP}$ working solution and $0.50 \mathrm{~mL}$ of $20 \%$ PEG-6000 were added to $5 \mathrm{~mL}$ graduated tubes successively. Then, the mixed solution was diluted to $3.0 \mathrm{~mL}$ with water and mixed well. Subsequently, the tubes were deposited in an ultrasonic reactor under ultrasonic irradiation $(59 \mathrm{kHz})$ for 20 min of incubation at room temperature. The RS spectra were recorded by means of synchronous scanning; the excited wavelength, $\lambda_{\mathrm{ex}}$, the emission wavelength, $\lambda_{\mathrm{em}},\left(\lambda_{\mathrm{ex}}-\lambda_{\mathrm{em}}=\Delta \lambda=\right.$ $0)$ and the RS intensity at $552 \mathrm{~nm}\left(I_{552 \mathrm{~nm}}\right)$ were recorded. The $I_{\mathrm{b}}$ values for the blank solutions without $\mathrm{CP}$ were also measured. The values $\Delta I=I_{552 \mathrm{~nm}}-I_{\mathrm{b}}$ were calculated.

\section{Results and Discussion}

It is known that the antibody was globulin, and most of the antigens also were protein. They were water-soluble macromolecular proteins, since they contained many amidogen and carboxyl residues in charges. Because the stereo structure anastomoses and the charge were opposite between GCP and $\mathrm{CP}$, they could attract and combine each other specifically. A nanogold particle has a high electron density, and easily combines with biological macromolecules, such as protein, DNA, RNA and glycoprotein. The nanogold conjugated with GCP to form nanogold-labeled GCP (AuGCP), which was proved by transmission electron microscopy (TEM), as shown in Fig. 1A. The AuGCP can combine with CP to form nanogold-labeled immunocomplexes in the presence of PEG by the van der Waals' force, the hydrophobic force, the Coulomb attracting force and the hydrogen bond binding force. After the immunoreaction, the nanogold particles would be released and aggregated to form bigger clusters, as shown in Fig. 1B. The aggregated nanogold particles resulted in an enhancement of $I_{552 \mathrm{~nm}}$. In a certain $\mathrm{CP}$ concentration range, with a raised concentration of $\mathrm{CP}$, more nanogold particles would be released, the stronger would be the aggregation degree of nanogold particles. ${ }^{25}$ The $I_{552 \mathrm{~nm}}$ become enhanced linearly with the CP concentration. Thus, an immunonanogold RS assay for CP was proposed. 


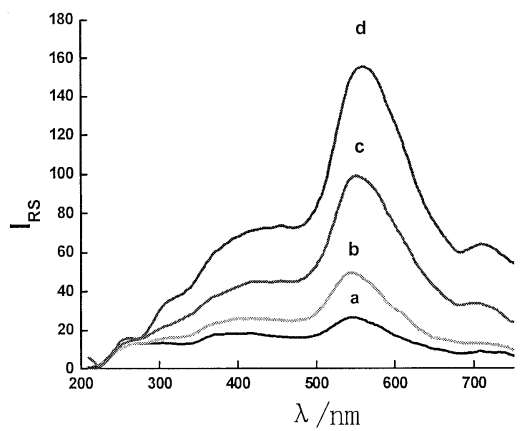

Fig. 2 RS spectra of the AuGCP-CP-PEG6000 system. a - d: pH, 7.8; AuGCP, $10.72 \mu \mathrm{g} / \mathrm{mL}$; PEG-6000, $33.33 \mathrm{mg} / \mathrm{mL}$. CP: a, 0; b, $0.18 ; \mathrm{c}, 0.72 ; \mathrm{d}, 1.26 \mu \mathrm{g} / \mathrm{mL}$.

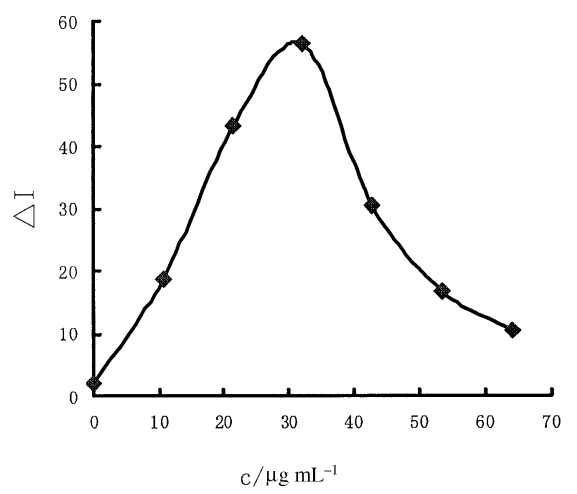

Fig. 3 Effect of the AuGCP concentration. pH, 7.8; CP, 0.36 $\mu \mathrm{g} / \mathrm{mL}$; PEG6000, $33.33 \mathrm{mg} / \mathrm{mL}$.

\section{Resonance scattering spectra}

GCP, CP and their immuno-complex have a weak RS signal, because both GCP and CP are water-soluble macromolecular proteins. Nanogold particles have a weak RS at $552 \mathrm{~nm}$. AuGCP also has weak RS peaks at that wavelength. After the immune reactions between AuGCP and CP took place under a suitable condition, the immuno-complex formed, and the coated nanogold particles were released from the AuGCP. The released gold nanoparticles aggregated in the presence of PEG, which led to a great enhancement of the intensity at $552 \mathrm{~nm}$ (Fig. 2). A wavelength of $552 \mathrm{~nm}$ was chosen for use.

\section{Selection of the $\mathrm{pH}$, type, and volume of buffer solution}

We tested the influence of $\mathrm{pH} 6.6-8.0$ on the $\Delta I$. When the $\mathrm{pH}$ was 7.8 , the system had the maximum $\Delta I$. A pH of 7.8 was chosen for use. We also tested the effect of citric acid- $\mathrm{Na}_{2} \mathrm{HPO}_{4}$ and $\mathrm{Na}_{2} \mathrm{HPO}_{4}-\mathrm{NaH}_{2} \mathrm{PO}_{4}, \mathrm{Na}_{2} \mathrm{HPO}_{4}-\mathrm{KH}_{2} \mathrm{PO}_{4}$ with a $\mathrm{pH}$ of 7.8 on $\Delta I$. The results demonstrated that $0.30 \mathrm{~mL}$ of a $\mathrm{pH} 7.8$ citric acid- $\mathrm{Na}_{2} \mathrm{HPO}_{4}$ buffer, gave the biggest $\Delta I$, and was thus chosen for use.

\section{Effect of the AuGCP concentration}

The influence of the AuGCP concentration on $\Delta I$ was studied. Figure 3 shows that in a certain range of concentrations, $\Delta I$ increased with an increase of the AuGCP concentration. $\Delta I$ attained the maximum when the AuGCP concentration was $10.72 \mu \mathrm{g} / \mathrm{mL}$. Thus, $10.72 \mu \mathrm{g} / \mathrm{mL}$ AuGCP was chosen.

\section{Effect of the PEG concentration}

PEG is a polymer of ethylene with no charge. A suitable

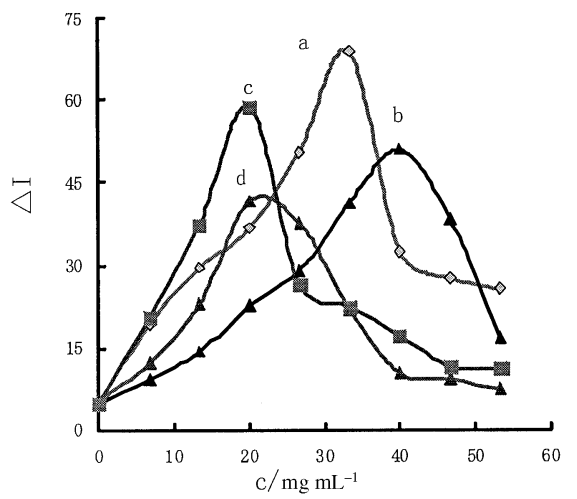

Fig. 4 Effect of deferent types of PEG and concentration on $\Delta I$. Conditions: $\mathrm{pH}, 7.8$; AuGCP, $10.72 \mu \mathrm{g} / \mathrm{mL}$; CP, $0.36 \mu \mathrm{g} / \mathrm{mL}$. PEG: a, 6000; b, 4000; c, 10000; d, 20000.

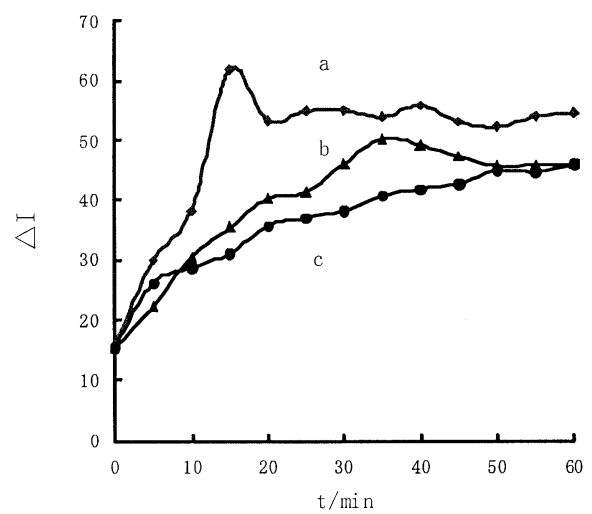

Fig. 5 Effect of the incubation time on $\Delta I$. Conditions: $\mathrm{pH}, 7.8$; AuGCP, $10.72 \mu \mathrm{g} / \mathrm{mL} ; \mathrm{CP}, 0.36 \mu \mathrm{g} / \mathrm{mL}$; PEG, 6000. a, $20^{\circ} \mathrm{C}$, ultrasonic irradiation; $\mathrm{b}, 37^{\circ} \mathrm{C} ; \mathrm{c}, 20^{\circ} \mathrm{C}$

concentration of PEG would lead to aggregation of the nanogold particles to enhance the detection signals. We considered the influence of PEG-4000, PEG-6000, PEG-10000 and PEG-20000 on $\Delta I$ (see Fig. 4). To a certain degree, the four PEG would enhance the $\Delta I$, maximum values of $\Delta I$ for the system occurring at a PEG-6000 concentration of $33.33 \mathrm{mg} / \mathrm{mL}$. Thus, 33.33 $\mathrm{mg} / \mathrm{mL}$ PEG-6000 was selected for use.

\section{Effect of the incubation time and the temperature}

The influence of the incubation time from 0 to $60 \mathrm{~min}$ on $\Delta I$ was investigated the results are shown in Fig. 5. Under ultrasonic irradiation at room temperature, the reaction was relatively quick, and the incubation time was evidently reduced. It was completed within $20 \mathrm{~min}$, and the $\Delta I$ value was comparatively stable. In $37^{\circ} \mathrm{C}$ water, the reaction was relatively slow, and the reaction completed within 40 min. However, at $20^{\circ} \mathrm{C}$ room temperature, the reaction was more slow, and the reaction still continued even after $60 \mathrm{~min}$. Thus, an incubation time of 20 min under ultrasonic irradiation was selected for use.

\section{Linear relationship}

Under the optimal condition, different $C_{\mathrm{CP}}$ values were tested, and working curves were drawn according the relationship between $C_{\mathrm{CP}}$ and their corresponding $\Delta I$. The data were linearly correlated according to the equation $\Delta I=101.0 C_{\mathrm{CP}}+1.8$, a correlation coefficient of $r=0.9970$ in the $0.0030-1.26 \mu \mathrm{g} / \mathrm{mL}$ concentration range and a $1.1 \mathrm{ng} / \mathrm{mL}$ detection limit (DL). The 
Table 1 Analytical features for the four PEG systems

\begin{tabular}{clccc}
\hline PEG & Regression equation & Linear range $/ \mu \mathrm{g} \mathrm{mL} \mathrm{L}^{-1}$ & Correlation coefficient & Detection limit/ng $\mathrm{mL}^{-1}$ \\
\hline PEG-4000 & $\Delta I=62.1 C_{\mathrm{CP}}+2.4$ & $0.0045-0.72$ & 0.9938 & 1.4 \\
PEG-6000 & $\Delta I=101.0 C_{\mathrm{CP}}+1.8$ & $0.0030-1.26$ & 0.9970 & 1.1 \\
PEG-10000 & $\Delta I=73.8 C_{\mathrm{CP}}+2.1$ & $0.0054-1.10$ & 0.9949 & 1.3 \\
PEG-20000 & $\Delta I=76.2 C_{\mathrm{CP}}+1.0$ & $0.0090-1.10$ & 0.9947 & 1.5 \\
\hline
\end{tabular}

Table 2 Analytical features for three immunonanogold AuGCP probes

\begin{tabular}{ccccc}
\hline $\begin{array}{c}\text { Nanogold } \\
\text { size/nm }\end{array}$ & $\begin{array}{c}\text { Regression } \\
\text { equation }\end{array}$ & $\begin{array}{c}\text { Linear range/ } \\
\mu \mathrm{mL}^{-1}\end{array}$ & $\begin{array}{c}\text { Correlation } \\
\text { coefficient }\end{array}$ & $\begin{array}{c}\text { Detection } \\
\text { limit/ } \\
\mathrm{ng} \mathrm{mL} \mathrm{mL}^{-1}\end{array}$ \\
\hline 10 & $\Delta I=73.2 C_{\mathrm{CP}}+3.4$ & $0.0038-1.08$ & 0.9913 & 1.6 \\
15 & $\Delta I=101.0 C_{\mathrm{CP}}+1.8$ & $0.0030-1.26$ & 0.9970 & 1.1 \\
30 & $\Delta I=144.7 C_{\mathrm{CP}}+3.1$ & $0.0046-0.54$ & 0.9953 & 3.1 \\
\hline
\end{tabular}

definition of DL was recommended by IUPAC in 1975, DL is expressed as $\mathrm{DL}=K S_{\mathrm{b}} / m$. Where $m$ and $S_{\mathrm{b}}$ represent the slope of the standard curve $(m=101.0)$ and the standard deviation of the blank value $\left(S_{\mathrm{b}}=0.0389, n=20\right)$, respectively. Based on the suggestion of IUPAC, $K=3$ was used to calculate DL. In addition, we tested the relationship between $C_{\mathrm{CP}}$ and their corresponding intensities, $\Delta I$, using $40 \mathrm{mg} / \mathrm{mL}$ PEG-4000, 20 $\mathrm{mg} / \mathrm{mL}$ PEG-10000, $20 \mathrm{mg} / \mathrm{mL}$ PEG-20000 were used as sensitizing agents, respectively. As shown in Table 1, the highest sensitivity and the widest linear range occurred in the presence of $33.33 \mathrm{mg} / \mathrm{mL}$ PEG-6000. Moreover, we also tested the relationship between $C_{\mathrm{CP}}$ and their corresponding intensities, $\Delta I$, for 10 and $30 \mathrm{~nm}$ immunonanogold AuGCP probes, respectively. As shown in Table 2, when a 15-nm immunonanogold AuGCP probe was chosen for the determination of $\mathrm{CP}$, the detection limit was lower, the linear range was wider, and the preparation of $15 \mathrm{~nm}$ nanogold was easy.

\section{Effect of foreign substances}

According to the procedure, the influence of foreign substances on the determination of $0.36 \mu \mathrm{g} / \mathrm{mL} \mathrm{CP}$ was tested. When the relative error was within $\pm 8 \%$, the tolerated amount for foreign substances was as listed in Table 3. The result showed that the foreign substances did not significantly interfere with the CP determination, which indicated that this method had good selectivity.

\section{Analysis of samples}

Ten sera samples were collected from the No. 5 Hospital of Guilin and diluted 40 -fold with water. A $100-\mu \mathrm{L}$ portion of the diluted samples was taken to determine the CP content according to the procedure. The samples were simultaneously determined by immunoturbidimetry. Using both assay results, a linear regress analysis was made, as shown in Fig. 6, with a slope value of 0.962 , a relative coefficient of 0.9964 and an intercept value of $20.5 \mu \mathrm{g} / \mathrm{mL}$. The results obtained with both assays were relatively good, and were consistent with published reference intervals for serum. ${ }^{5}$

\section{Conclusion}

Nanogold particles of size $15 \mathrm{~nm}$ were prepared simply, and were easy to be labeled. In this paper, $15 \mathrm{~nm}$ gold nanoparticles
Table 3 Effect of coexisting substances $(0.36 \mu \mathrm{g} / \mathrm{mL} \mathrm{CP})$

\begin{tabular}{lcc}
\hline Coexistent substance & Allowable conc. $/ \mathrm{\mu g} \mathrm{mL}^{-1}$ & Relative error, \% \\
\hline L-Lysine & 40 & +5.9 \\
Urea & 200 & -5.7 \\
$\mathrm{BSA}$ & 5 & +7.7 \\
Histidine & 20 & +6.6 \\
L-Cystine & 5 & -2.3 \\
Glycine & 250 & +5.9 \\
L-Tyrosine & 39 & +7.3 \\
DL-Tryptophan & 27 & -6.6 \\
$\mathrm{VB}_{6}$ & 10 & -7.8 \\
$\mathrm{VB}_{1}$ & 20 & -4.3 \\
$\mathrm{DL}-\mathrm{Aspartic}$ acid & 50 & -5.3 \\
$\mathrm{Nicotinic}$ acid & 10 & -6.7 \\
$\mathrm{IgG}$ & 4 & +4.9 \\
$\mathrm{Vc}$ & 150 & -5.1 \\
$\mathrm{HSA}_{\mathrm{Sl}}$ & 7 & -7.3 \\
$\mathrm{Glucose}_{\mathrm{Sucrose}}$ & 33 & -6.7 \\
$\mathrm{Creatine}_{\mathrm{Co}}^{2+}, \mathrm{SO}_{4}^{2-}$ & 33 & +4.1 \\
$\mathrm{Zn}^{2+}, \mathrm{SO}_{4}^{2-}$ & 5 & +7.3 \\
$\mathrm{Ni}^{2+}, \mathrm{Cl}^{-}$ & 6 & -6.9 \\
$\mathrm{Cu}^{2+}, \mathrm{SO}_{4}^{2-}$ & 11 & -5.5 \\
\hline
\end{tabular}

were used to label GCP to obtain an immunonanogold RS probe for $\mathrm{CP}$. Based on the immunoreaction between the probe and $\mathrm{CP}$, and the RS effect of nanogold, a simple and sensitive immunonanogold RS assay has been proposed for the determination of $\mathrm{CP}$ with high sensitivity and good selectivity. This assay has been applied to detect $\mathrm{CP}$ in real samples, with satisfactory results.

\section{Acknowledgements}

This work was supported by the National Natural Science Foundation of China (Grant 20036001, 20667001), Natural Science Foundation of Guangxi (Grant 0728213), and the Foundation of New Century Ten-Hundred-Thousand Talents of Guangxi.

\section{References}

1. F. Young, W. E. Friedrichs, R. L. Cupples, M. J. Bonifacio, J. A. Sanford, and W. A. Horton, J. Biol. Chem., 1990, 265 , 10780.

2. J. Banha, L. Marques, R. Oliveira, M. Fátima Martins, E. Paixão, D. Pereira, R. Malhó, D. Penque, and L. Costa, Free Radical Biol. Med., 2008, 44, 483.

3. P. L. Fox, C. Mukhopadhyay, and E. Ehrenwald, Life Sci., $\mathbf{1 9 9 5}, 56,1749$.

4. S. J. Sun and J. Yang, J. Health Care Med. Chin. PLA, 


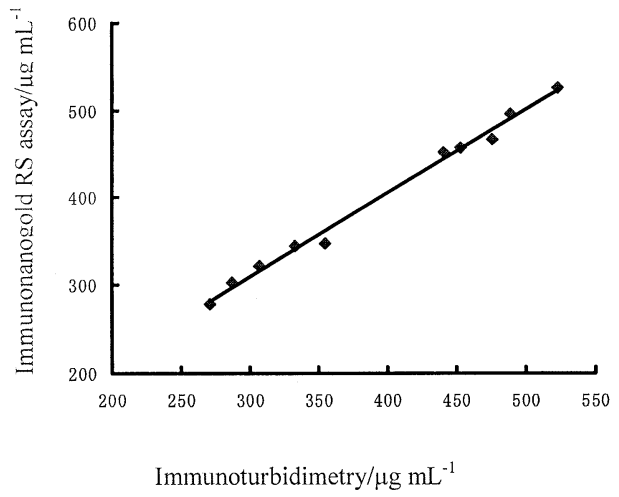

Fig. 6 Linear regress analysis.

2002, 4, 220

5. E. Cauza, T. Maier-Dobersbergeri, C. Polli, K. Kaserer, L. Krameri, and P. Ferenci, J. Hepatol., 1997, 27, 358.

6. Y. K. Fan, F. M. Si, and L. J. Xiong, Henan J. Practical Nervons Dis., 2001, 4, 72.

7. F. W. Sunderman and S. Nomoto, Clin. Chem., 1970, 16, 903.

8. K. H. Schosinsky, H. P. Lehmann, and M. F. Beeler, Clin Chem., 1974, 20, 1556.

9. J. J. Mule, Clin. Invest., 2000, 105, 707.

10. P. D. Vise, K. Kodali, N. Hoe, A. Paszczynski, J. M. Musser, and G. W. Daughdrill, Protein Expression Purif., 2003, 32, 232.

11. Z. Y. Guo, Z. Tian, and Y. L. Jia, Spec. Spectr. Anal., 2004, 24, 596.

12. E. G. Matveeva, Z. Gryczynski, J. Malicka, J. Lukomska, S. Makowiec, K. W. Berndt, J. R. Lakowicz, and I. Gryczynski, Anal. Biochem., 2005, 344, 161.

13. S. M. Han, J. H. Cho, I. H. Cho, E. H. Paek, H. B. Oh, B. S. Kim, C. Ryu, K. Lee, Y. K. Kim, and S. H. Paek, Anal. Chim. Acta, 2007, 587, 1.

14. D. A. Johnson, S. Osaki, and E. Frieden, Clin. Chem., 1967, 13,142 .
15. G. J. Buffone, E. M. Brett, S. A. Lewis, M. Losefsohn, and J. M. Hicks, Clin. Chem., 1979, 25, 749.

16. J. J. Cunningham, M. K. Lydon, R. Emerson, and P. R. Harmatz, Nature, 1996, 12, 83.

17. F. Dati, M. Lammers, A. Adam, D. Sondag, and L. Stienen, Lab. Med., 1989, 13, 87.

18. H. Mukerjee, Clin. Chem., 1990, 36, 391.

19. B. L. Somani and V. Ambade, Clin. Biochem., 2007, 40, 571.

20. L. M. Ao, F. Gao, B. F. Pan, D. X. Cui and R. He, J. Shanghai Jiaotong Univ., 2006, 40, 1448.

21. A. P. Fan, C. Y. Liu, Z. X. Liao, J. Y. Liang, and J. Z. Lu, Chin. J. Anal. Chem., 2006, 34, 35.

22. Z. P. Li, C. H. Liu, Y. S. Fan, Y. C. Wang, and X. R. Duan, Anal. Bioanal. Chem., 2006, 359, 247.

23. C. Zhang, Z. Zhang, B. Yu, J. Shi, and X. Zhang, Anal. Biochem., 2002, 74, 96.

24. V. I. Baranov, Z. Quinn, D. R. Bandura, and S. D. Tanner, Anal. Chem., 2002, 74, 1629.

25. Z. L. Jiang, S. J. Sun, A. H. Liang, W. X. Huang, and A. M. Qin, Clin. Chem., 2006, 52, 1389.

26. Z. L. Jiang, W. X. Huang, J. P. Li, M. S. Li, A. H. Liang, S. S. Zhang, and B. Chen, Clin. Chem., 2008, 54, 116.

27. Z. H. Mo, H. J. Huang, and L. H. Zhu, Chem. J. Chin. Univ., 2007, 28, 649.

28. J. Das, M. A. Aziz, and H. Yang, J. Am. Chem. Soc., 2006, 128,16022

29. Y. Q. He, S. P. Liu, Q. Liu, Z. F. Liu, and X. L. Hu, Sci. China, Ser. B: Chem., 2005, 35, 159.

30. A. H. Liang, Z. L. Jiang, B. M. Zhang, Q. Y. Liu, and X. Lu, Anal. Chim. Acta, 2005, 530, 131.

31. C. Z. Huang, Y. F. Li, and X. D. Liu, Anal. Chim. Acta, 1998, 375, 87.

32. R. P. Jia, H. L. Zhai, Y. Shen, X. G. Chen, and Z. D. Hu, Talanta, 2004, 64, 355.

33. C. X. Zhang, Y. Zhang, X. Wang, Z. M. Tang, and Z. H. Lu, Anal. Bioanal. Chem., 2003, 320, 136.

34. Z. L. Jiang, M. J. Zou, and A. H. Liang, Clin. Chim. Acta, 2008, 387, 24.

35. M. Hou, S. J. Sun, and Z. L. Jiang, Talanta, 2007, 72, 463. 